PUBLIK: Jurnal Manajemen Sumber Daya Manusia, Adminsitrasi dan Pelayanan Publik

Sekolah Tinggi Ilmu Administrasi Bina Taruna Gorontalo

Volume VIII Nomor 1, 2021

\title{
PENGARUH KEPRIBADIAN WIRAUSAHA, EKSPEKTASI PENDAPATAN DAN MOTIVASI TERHADAP MINAT BERWIRAUSAHA
}

\author{
Aprilia Tutik Widianingsih \\ Universitas Sarjanawiyata Tamansiswa \\ apriliatutik54@gmail.com
}

\begin{abstract}
ABSTRAK
Penelitian ini bertujuan untuk mengetahui pengaruh kepribadian wirausaha, ekspektasi pendapatan dan motivasi terhadap minat berwirausaha mahasiswa. Penelitian ini bersifat deskritif kuantitatif dengan Teknik pengambilan sampel purposive sampling. Metode pengumpulan data dalam penelitian ini menggunakan data mentah yang diperoleh melalui survei kuesioner. Sampel dalam penelitian ini berjumlah 130 responden mahasiswa di Yogyakarta.Uji asumsi klasik meliputi uji normalitas, uji multi kolinearitas, dan uji hetero kedastisitas. Teknik analisis data menggunakan analisis regresi berganda, koefisien determinasi $\left(\mathrm{R}^{2}\right)$, koefisien regresi dan uji t. Hasil penelitian ini menunjukkan bahwa (1) kepribadian wirausaha berpengaruh positif dan signifikan terhadap minat berwirausaha mahasiswa. (2) terdapat pengaruh positif dan tidak signifikan Ekspektasi pendapatan terhadap Minat Berwirausaha Mahasiswa di Yogyakarta, (3) Motivasi berpengaruh positif dan signifikan terhadap minat berwirausaha mahasiswa.
\end{abstract}

Kata Kunci: Ekspektasi Pendapatan, Kepribadian Wirausaha, Motivasi, Minat Berwirausaha

\section{ABSTRAC}

This study aims to determine the effect of entrepreneurial personality, income expectations and motivation on student entrepreneurial interest in Yogyakarta. This research is descriptive quantitative with sampling technique. The data collection method in this study uses primary data obtained through a questionnaire. The sample used in this study were 130 respondents aimed at special student in the Yogyakarta area. The classical assumption test includes normality test, multicollinearity test, and heteroscedasticity test. The data analysis technique used multiple regression analysis, the coefficient of determination $\left(R^{2}\right)$ the regression coefficient and the $t$ test. The result of this study indicate that (1) there is a positive and significant influence of Entrepreneurial Perssonality on Student Entrepreneurial Interest in Yogyakarta (2) there is a positive and significant effect of income expectations on Student Entrepreneurial interest in Yogyakarta, (3) there is a positive and significant influence on motivation towards Student Entrepreneurial Interest in Yogyakarta.

Keywords: Income Expectations, Entrepreneurial Personality, Motivation, Entrepreneurial Interest 


\section{PENDAHULUAN}

Indonesia memiliki sumber daya manusia yang banyak, setiap tahun banyak lulusan perguruan tinggi negeri dan swasta, mereka adalah pekerja semu dan mereka sangat membutuhkan pekerjaan untuk menghasilkan uang. Apabila jumlah sumber daya manusia yang banyak tidak dapat diimbangi dengan baik oleh kualitas sumber daya manusia tersebut, maka akan timbul permasala hanya itu pengangguran. Berdasarkan data Badan Pusat Statistik tahun 2017 hingga 2018, tingkat pengangguran terbuka (TPT) provinsi mencapai 2,84 pada Februari 2017, dan meningkat 3,02 pada Agustus. Mencapai 3,06 pada Februari 2018 hingga 3,35 pada Agustus. (www.bps.go.id). Rata-rata, lulusan perguruan tinggi dan swasta lebih bersedia bekerja di lembaga pemerintah dan swasta yang berpenghasilan lebih tinggi dari pada dalam menciptakan lapangan kerja baru atau berwirausaha.

Hal ini menunjukkan bahwa minat mahasiswa untuk menjadi wirausaha masih rendah. Menurut Setiawan dan Sukanti (2016), berwirausaha adalah "usaha seseorang untuk menciptakan lapangan kerja sendiri baik membuka usaha atau menciptakan sesuatu yang baruguna meningkatkan perekonomian bagi dirinya maupun bagi orang lain" (Setiabudi, 2019). Oleh karena itu, diperlukan pembinaan atau pembinaan kepada mahasiswa agar tidak hanya berorientasi pada pencari kerja, tetapi juga siap menjadi pencipta lapangan kerja, karena menumbuhkan kewirausahaan di kalangan mahasiswa dapat menekan angka pengangguran tahunan. Seperti yang dikemukakan oleh Buchori (2011:1). Dunia wirausaha itu penting, karena semakin Negara itu maju maka banyak orang yang sudah terdidik dan maju mundurnya perekonomian itu yang mendukung adalah wirausaha. Adapun cara menumbuhkan jiwa kewirausahaan mahasiswa, dengan menanamkan minat berwirausaha mahasiswa. (Setiawan \& Sukanti, 2016). Adanya minat berwirausaha dapat dilihat dari kesediaan seseorang dalam melakukan pekerjaan, tekun dalam hal yang dapat mencapai kemajuan usahanya, kesediaan dalam menanggung apapun risiko yang akan terjadi pada usahanya. Menurut Karabulut (2016) mengatakan bahwa niat berwirausaha didasarkan oleh visi, mimpi, perasaan untuk berwirausaha, pengembangan rencana bisnis, akuisisi sumber daya dan perilaku yang diarahkan oleh tujuan. Niat untuk berwirausaha berarti dapat muncul melalui adanya kemauan untuk membuat usaha, perencanaan usaha bisnis dengan tujuan usaha dalam diri seseorang. (Setiabudi, 2019)

Dewi (2010) menyatakan bahwa ada 2 (dua) faktor yang mempengaruhi minat berwirausaha mahasiswa yaitu faktor intrinsik dan faktor ekstrinsik. Faktor intrinsic terdiri dari perasaan dan emosi, pendapatan, motivasi dan cita-cita, dan harga diri. Sedangkan faktor ekstrinsik terdiri dari dukungan lingkungan keluarga, lingkungan masyarakat, 
peluang, dan pendidikan dan pengetahuan (Santosa, 2016). Dalam menumbuhkan minat berwirausaha, seseorang harus memiliki kepribadian yang tinggi untuk memfasilitas iusaha yang dilakukan oleh kepribadian yang bersangkutan, yaitu wirausahawan yang memiliki kepercayaan diri, kepemimpinan, orientasi tugas dan hasil serta dapat menghadapi risiko di masa depan. Achmad dan Nandiswara (2014) mengungkapkan bahwa niat memainkan peranan yang mengarah pada tindakan melalui pertimbangan yang mendalam, diyakini dan diinginkan seseorang (Setiabudi, 2019). Namun masih banyak mahasiswa yang belum berani untuk mencoba menciptakan lapangan pekerjaan, mereka beranggapan bahwa memilih jalan untuk berwirausaha akan selalu gagal di masa depan.

Menciptakan lapangan pekerjaan kenyataannya dapat memperoleh pendapatan yang tinggi dibandingkan bekerja di instansi pemerintah. Keinginan untuk menghasilkan uang adalah alasan minat berwirausaha (Suhartini:2011) (Santosa, 2016). Penghasilan yang diharapkan akan menumbuhkan jiwa berwirausaha siswa. Semakin tinggi penghasilan yang diharapkan maka semakin tinggi pula minat siswa untuk berwirausaha. Minat adalah proses motivasi yang kuat yang member energi pada pembelajaran, membimbing dalam bidang akademis dan karir, serta sangat penting bagi kesuksesan siswa (Judith, Jessi, \& Stacy,. 2016) (Munawar \& Supriatna, 2018). Namun sampai saat ini masih banyak mahasiswa yang beranggapan bahwa pendapatan berwirausaha itu rendah, maka dari itu mahasiswa lebih memilih untuk bekerja di perusahaan.

Alma (2010:89) mengemukakan bahwa motivasi adalah kemauan untuk berbuat sesuatu, sedangkan motif adalah kebutuhan, keinginan, dorongan, atau impuls (Zuhrina Aidha, 2016). Motivasi adalah segala hal yang dapat menggugah motivasi atau semangat seseorang untuk melakukan sesuatu. Oleh karena itu minat berwirausaha sangat dipengaruhi oleh motivasi intrinsik.. Jika seseorang sudah termotivasi untuk menjadi wirausahawan sukses, maka akan muncul minat yang tinggi untuk kemudian akan melakukan upaya terbaik

Dalam penelitian ini, penulis mengambil faktor kepribadian wirausaha, ekspektasi pendapatan dan motivasi sebagai variabel. Berdasarkan permasalahan tersebut, peneliti ingin melakukan penelitian yang berjudul "Analisis Kepribadian Wirausaha, Ekspektasi Pendapatan dan Motivasi terhadap Minat Berwirausaha" (Studi kasus Mahasiswa di Yogyakarta). Adapun tujuan dari penelitian ini yaitu untuk mengetahui seberapa pengaruhnya Kepribadian Wirausaha, Ekspektasi Pendapatan dan Motivasi terhadap minat mahasiswa di Yogyakarta dalam berwirausaha. 


\section{METODE PENELITIAN}

Penelitian ini merupakan penelitian yang bersifat deskriptif kuantitatif yaitu mendeskripsikan atau menggambarkan data yang terkumpul yang berwujud angka-angka atau menggunakan alat statistik. Teknik pengambilan data pada penelitian ini menggunakan kuesioner. Populasi penelitian ini adalah mahasiswa di Yogyakarta yang berjumlah 130 responden.

Populasi adalah keseluruhan subyek penelitian. Sugiyono (2010:117) menjelaskan bahwa, populasi adalah wilayah generalisasi yang terdiri atas: obyek/subyek yang mempunyai kualitas dan karakteristik tertentu yang ditetapkan oleh peneliti untuk dipelajari dan kemudian ditarik kesimpulan (Anoraga, 2015). Mengacu dari pendapat tersebut maka dalam penelitian ini yang menjadi populasi adalah mahasiswa di Yogyakarta dengan jumlah 130 orang.

Sampel adalah bagian dari jumlah dan karakteristik yang dimiliki oleh populasi (Sugiyono, 2010: 118) (Anoraga, 2015). Dalam penelitian ini ditentukan jumlah sampel melalui alternatif lain yaitu melalui jumlah item-item pertanyaan pada kuesioner, dengan mengalikan 5x jumlah pertanyaan. Dengan demikian jumlah sampel untuk penelitian ini adalah 26 x 5 atau 130 responden.

Untuk memudahkan dalam pengujian hipotesis, maka peneliti menetapkan variabel penelitian sebagai berikut:

1. Variabel bebas atau Independent Variable (X)

a. Variabel Kepribadian Wirausaha. Kepribadian adalah karakter yang dimiliki oleh seseorang. Dalam kepribadian seorang individu terdapat rasa percaya diri, berorientasi pada tugas dan hasil, berani mengambil risiko, berjiwa pemimpin, keorisinilan dan berorientasi kedepan (Syaifudin, 2017).

b. Penghasilan yang diharapkan adalah pengharapan seseorang atas penghasilan yang diperolehnya dari kegiatan usaha atau pekerjaan. Sebagai seorang wirausaha, diharapkan mendapatkan penghasilan yang lebih tinggi dibandingkan sebagai karyawan perusahaan. Berwirausaha akan mendatangkan pendapatan yang besar dan tidak terbatas, tetapi pendapatan dari wirausaha tidak dapat diprediksi, terkadang dapat melebihi pendapatan yang diharapkan, terkadang dapat melebihi pendapatan yang diharapkan. (Setiawan, 2016) (Santosa, 2016)

c. Variabel Motivasi. Menurut Saiman (2014:26) ada beberapa indikator Motivasi yaitu laba, kebebasan, impian personal. (Mahardika et al., 2019). 
2. Variabel terikat atau Dependent Variable (Y)

Indikator Minat Berwirausaha terdapat jiwa kepemimpinan, tidak ada ketegantungan, berorientasi pada masa depan, membantu lingkungan sosial.

\section{HASIL PEMBAHASAN}

\section{Uji Validitas dan Uji realibilitas}

\section{1) Uji Validitas}

Uji signifikan dilakukan dengan membandingkan $r$ hitung dengan $r$ tabel $(r$ hitung> $r$ tabel ) maka butir pertanyaan tersebut dinyatakan valid ataupun sebaliknya, untuk menguji derajat kebebasan $\mathrm{df}=\mathrm{n}-\mathrm{k}(\mathrm{df}=130-2=128)$ diperoleh $\mathrm{r}$ tabel sebesar 0,1449 dengan uji satu arah. Untuk r tiap butir dapat dilihat pada kolom (Corrected item total correlation). Hasil Uji Validitas ditunjukkan pada tabel berikut.

\section{Tabel 1}

\section{Hasil Uji Validitas Kepribadian Wirausaha}

\begin{tabular}{|c|c|c|c|c|}
\hline Variabel & Butir & r hitung & $\mathrm{r}$ tabel & keterangan \\
\hline \multirow{6}{*}{ Motivasi } & M1 & 0.546 & 0.1449 & Valid \\
\hline & M2 & 0.787 & 0.1449 & Valid \\
\hline & M3 & 0.756 & 0.1449 & Valid \\
\hline & M4 & 0.659 & 0.1449 & Valid \\
\hline & M5 & 0.628 & 0.1449 & Valid \\
\hline & M6 & 0.677 & 0.1449 & Valid \\
\hline
\end{tabular}

Sumber : Data Primer, diolah, 2020

\section{Tabel 2}

\section{Hasil Uji Validitas Ekspektasi Pendapatan}

\begin{tabular}{lllll}
\hline \multirow{2}{*}{ Variabel } & Butir & hitung & r tabel & Keterangan \\
\hline \multirow{3}{*}{ Ekspektasi } & EP1 & 0.771 & 0.1449 & Valid \\
pendapatan & 0.739 & 0.1449 & Valid \\
& EP3 & 0.788 & 0.1449 & Valid \\
& EP4 & 0.794 & 0.1449 & Valid \\
\hline \multicolumn{5}{c}{ Sumber : Data Primer, diolah, 2020 }
\end{tabular}

Sumber : Data Primer, diolah, 2020 


\section{Tabel 3}

\section{Hasil Uji Validitas Motivasi}

\begin{tabular}{|c|c|c|c|c|}
\hline Variabel & Butir & $\mathrm{r}$ hitung & $\mathrm{r}$ tabel & keterangan \\
\hline \multirow{6}{*}{ Motivasi } & M1 & 0.546 & 0.1449 & Valid \\
\hline & M2 & 0.787 & 0.1449 & Valid \\
\hline & M3 & 0.756 & 0.1449 & Valid \\
\hline & M4 & 0.659 & 0.1449 & Valid \\
\hline & M5 & 0.628 & 0.1449 & Valid \\
\hline & M6 & 0.677 & 0.1449 & Valid \\
\hline
\end{tabular}

Sumber : Data Primer, diolah, 2020

Tabel 4

\section{Hasil Uji ValiditasMinatBerwirausaha}

\begin{tabular}{cllll}
\hline \multirow{4}{*}{ Variabel } & Butir & hitung & r tabel & Keterangan \\
\hline & MB1 & 0.706 & 0.1449 & Valid \\
& MB2 & 0.697 & 0.1449 & Valid \\
& MB3 & 0.566 & 0.1449 & Valid \\
Minat & MB4 & 0.569 & 0.1449 & Valid \\
Berwirausaha & MB5 & 0.737 & 0.1449 & Valid \\
& MB6 & 0.765 & 0.1449 & Valid \\
& MB7 & 0.667 & 0.1449 & Valid \\
& MB8 & 0.694 & 0.1449 & Valid \\
\hline
\end{tabular}

Sumber : Data Primer, diolah, 2020

Hasil perhitungan koefisien korelasi seluruhnya mempunyai $r$ hitung yang lebih besardari $r$ tabel ( $r$ hitung $>r$ tabel) $(0,1449)$. Dengan demikian dapat disimpulkan bahwa seluruh butir dinyatakan valid. 


\section{2) Uji Reabilitas}

\section{Tabel 5}

\begin{tabular}{lccl}
\multicolumn{4}{c}{ Hasil Uji Realibilitas } \\
Variabel & $\begin{array}{c}\text { Cronbach's } \\
\text { Alpha Based } \\
\text { on } \\
\text { Standaridized } \\
\text { items }\end{array}$ & $\begin{array}{c}\text { Nilai } \\
\text { Kritis }\end{array}$ & Keterangan \\
\hline Kepribadian Wirausaha & 0.899 & 0.60 & Reliabel \\
Ekspektasi Pendapatan & 0.898 & 0.60 & Reliabel \\
Motivasi & 0.874 & 0.60 & Reliabel \\
Minat Berwirausaha & 0.899 & 0.60 & Reliabel \\
\hline
\end{tabular}

Sumber : Data Primer, diolah, 2020

Dari data tersebut menujukkan bahwa semua variabel mempunyai koefisien lebih besar dari 0,60 sehinggap dapat disimpulkan semua variabel-variabel yang digunakan dalam penelitian ini adalah reliabel dan layak digunakan sebagai alat ukur dalam pengumpulan data.

\section{Teknik Analisis Data}

\section{1) Uji Normalitas}

\section{Tabel 6}

\section{Hasil Uji Normalitas}

\begin{tabular}{lcc}
\hline $\begin{array}{l}\text { Kolmogorov- } \\
\text { Smirov } \boldsymbol{Z}\end{array}$ & Sig. & Keterangan \\
\hline 1,277 & 0,077 & Data Normal \\
\hline \multicolumn{2}{c}{ Sumber: Data Primer, diolah, 2020}
\end{tabular}

Data berdistribusi normal jika nilai signifikasinya> 0,05. Dilihat dari tabel 6 uji Kolmogorov-Smirnov maka dapat dinyatakan bahwa data tesebut berdistribusi normal dikarenakan Asym.Sig lebih besar dari signifikasi 0,05 yaitu menunjukkan 0.077 > 0,05 . 


\section{2) Uji Multikolinearitas}

\section{Tabel 7}

\section{Hasil Uji Multikolinearitas}

\begin{tabular}{llll}
\hline Variabel & Tolerance & VIF & Keterangan \\
\hline X1 & 0,314 & 3,181 & $\begin{array}{l}\text { Tidak terjadi } \\
\text { multikolinearitas }\end{array}$ \\
\hline X2 & 0,370 & 2,703 & $\begin{array}{l}\text { Tidak terjadi } \\
\text { multikolinearitas }\end{array}$ \\
\hline X3 & 0,235 & 4,250 & $\begin{array}{l}\text { Tidak terjadi } \\
\text { multikolinearitas }\end{array}$ \\
\hline
\end{tabular}

Sumber : Data Primer, diolah, 2020

Dari tabel7 di atas dapat diketahui nilai variance inflaction factor (VIF) ketiga variabel KW (Kepribadian Wirausaha) $=3.181$, EP (Ekspektasi Pendapatan) $=2.703$, dan $\mathrm{M}$ (Motivasi) $=4.250$ leblh kecil dari 5, sehingga dapat disimpulkan bahwa antar variabel independent tidak terjadi masalah multikolinearitas.

\section{3) Uji Heterokedastisitas}

\section{Gambar 1}

\section{Hasil Uji Heterokedastisitas}

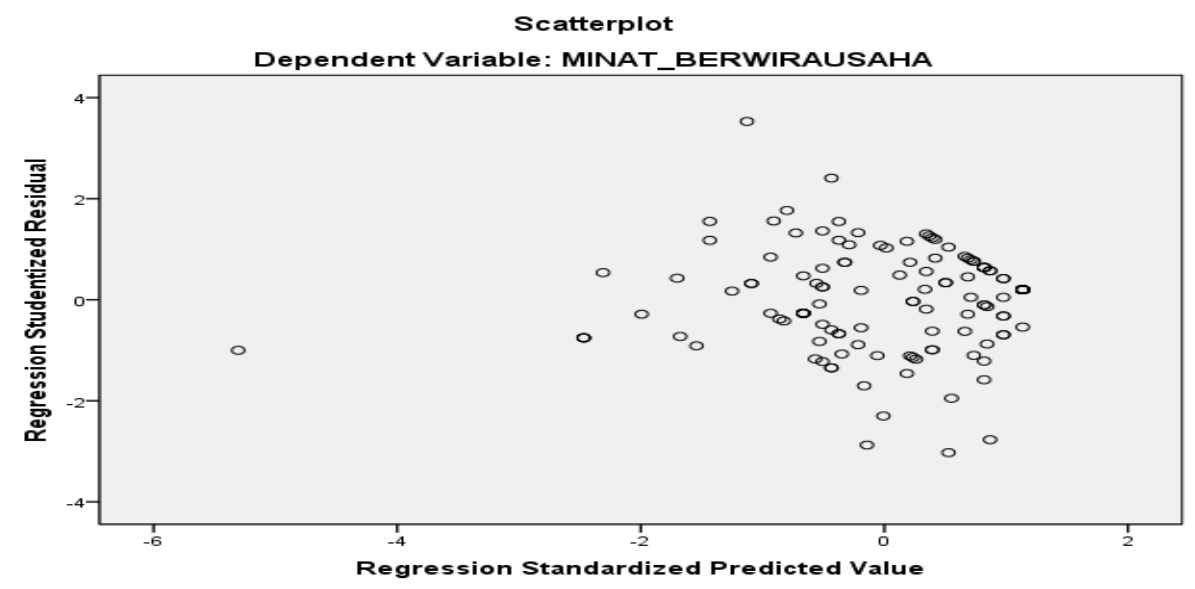

Dari gambar1 di atas terlihat bahwa terlihat tidak adanya pola yang jelas, dan titik-titik tersebar di atas dan di bawah angka 0 dan sumbu Y. Dapat disimpulkan bahwa tidak terdapat heteroskedastisitas pada model regresi ini. 


\section{Uji Regresi Linear Berganda}

Pada tabel 8, menunjukkan adanya pengaruh positif variabel bebas yaitu kepribadian wirausaha (X1), Ekspektasi Pendapatan (X2), dan Motivasi (X3) terhadap variabel terikat yaitu Minat Berwirausaha (Y). tabel di atas juga menunjukkan variabel yang paling dominan yang dapat dilihat dari kolom Unstandarized Coefficients B, kolom tersebut menunjukkan Motivasi memiliki angka yang paling tinggi $(0,648)$ dibandingkan dengan variabel lain.

\section{Tabel 8}

\section{Hasil Uji Regresi Linear Berganda}

\begin{tabular}{|c|c|c|c|c|c|c|}
\hline \multicolumn{7}{|c|}{ Coefficients $^{\mathrm{a}}$} \\
\hline \multirow[t]{2}{*}{ Mod } & & \multicolumn{2}{|c|}{ Unstandardized Coefficients } & \multirow{2}{*}{$\begin{array}{c}\begin{array}{c}\text { Standardized } \\
\text { Coefficients }\end{array} \\
\text { Beta }\end{array}$} & \multirow[b]{2}{*}{$t$} & \multirow[b]{2}{*}{ Sig. } \\
\hline & & $B$ & Std. Error & & & \\
\hline \multirow[t]{4}{*}{1} & (Constant) & 3.282 & 1.882 & & 1.744 & .084 \\
\hline & $\begin{array}{l}\text { KEPRIBADIAN_ } \\
\text { WIRAUSAHA }\end{array}$ & .322 & .091 & .304 & 3.555 & .001 \\
\hline & $\begin{array}{l}\text { EKSPEKTASI } \\
\text { PENDAPATAN }\end{array}$ & 186 & .125 & 117 & 1.492 & .138 \\
\hline & MOTIVASI & .648 & 134 & .477 & 4.837 & .000 \\
\hline
\end{tabular}

Sumber : Data Primer, diolah, 2020

\section{Koefisien Determinasi $\left(\mathbf{R}^{2}\right)$}

Tabel 9

\section{Hasil Koefisien Determinasi}

\begin{tabular}{|l|l|l|l|l|}
\hline Model & $\mathrm{R}$ & $\begin{array}{l}\mathrm{R} \\
\text { Square }\end{array}$ & $\begin{array}{l}\text { Adjusted } \\
\mathrm{R} \text { Square }\end{array}$ & $\begin{array}{l}\text { Std. Error } \\
\text { of the } \\
\text { Estimate }\end{array}$ \\
\hline 1 & 0,843 & 0,717 & 0,704 & 2,507 \\
\hline
\end{tabular}

Sumber : Data Primer, diolah, 2020

Dari tabel 9 diketahui bahwa variabel independent mempengaruhi variabel dependen sebesar 0,704 dilihat dari kolom Adjusted $R$ Square. Hal ini dapat disimpulkan bahwa variabel independent X1 Kepribadian wirausaha, X2 Ekspektasi 
pendapatan, X3 Motivasi yang berpengaruh terhadap variabel dependen Y Minat wirausaha sebesar 70,4\% dan sisanya dipengaruhi oleh variabel lain.

\section{Uji t}

\section{Tabel 9}

\section{Hasil KoefisienRegresi dan Uji t}

\begin{tabular}{|c|c|c|c|c|c|c|}
\hline \multicolumn{7}{|c|}{ Coefficients $^{\mathrm{a}}$} \\
\hline \multirow[t]{2}{*}{ Mode } & & \multicolumn{2}{|c|}{ Unstandardized Coefficients } & \multirow{2}{*}{$\begin{array}{c}\begin{array}{c}\text { Standardized } \\
\text { Coefficients }\end{array} \\
\text { Beta }\end{array}$} & \multirow[b]{2}{*}{ t } & \multirow[b]{2}{*}{ Sig. } \\
\hline & & B & Std. Error & & & \\
\hline \multirow[t]{4}{*}{1} & (Constant) & 3.282 & 1.882 & & 1.744 & .084 \\
\hline & $\begin{array}{l}\text { KEPRIBADIAN_ } \\
\text { WIRAUSAHA }\end{array}$ & .322 & .091 & .304 & 3.555 & .001 \\
\hline & $\begin{array}{l}\text { EKSPEKTASI } \\
\text { PENDAPATAN }\end{array}$ & .186 & .125 & .117 & 1.492 & .138 \\
\hline & MOTIVASI & .648 & .134 & .477 & 4.837 & .000 \\
\hline
\end{tabular}

a. Dependent Variable: MNAT_BERWIRAUSAHA

Sumber : Data Primer, diolah, 2020

Pembuktian terhadap variabel independent berpengaruh signifikasi atau tidak terhadap variabel dependen adalah dengan cara membandingkan nilai $t$ hitung dengan $t$ tabel serta tingkat signifikasinya berada di bawah 0,05. Apabila nilai $t$ hitung $>\mathrm{t}$ tabel maka Ha diterima dan Ho ditolak. Sebaliknya jika $\mathrm{t}$ hitung $<\mathrm{t}$ tabel maka Ha ditolak dan Ho diterima. Tabel9 dapat dijelaskan sebagai berikut:

\section{1) Pengujian hipotesis 1}

Variabel kepribadian wirausaha memiliki tingkat signifikasi sebesar 0.001. Maka tingkat signifikasi lebih besar dari $0,05(0,001<0,05)$ dan hasil nilai t hitung sebesar 3,555 lebih besar dari t tabel 1,6568 atau t hitung 3,555> t table 1,6568, Hal ini membuktikan bahwa Ha di terima dan Ho di tolak, sehingga disimpulkan bahwa kepribadian wirausaha berpengaruh positif dan signifikasi terhadap minat berwirausaha

2) Pengujian hipotesis 2

Variabel Ekspektasi pendapatan menunjukkan nilai t hitung sebesar 1,492 lebih kecil dari t tabel 1,6568 atau t hitung 1,492 < t tabel 1,6568 dan hasil signifikansi yang diperoleh sebesar $0,138>0,05$, hal ini membuktikan jika Ha ditolak dan Ho diterima, sehingga disimpulkan ekspektasi pendapatan tidak berpengaruh positif dan tidak signifikanasi terhadap minat berwirausaha.

3) Pengujian hipotesis 3 
PUBLIK: Jurnal Manajemen Sumber Daya Manusia, Adminsitrasi dan Pelayanan Publik Sekolah Tinggi Ilmu Administrasi Bina Taruna Gorontalo Volume VIII Nomor 1, 2021

Variabel Motivasi memiliki tingkat signifikasi sebesar 0,000. Maka tingkat signifikasi lebih kecil dari 0,05 $(0,000<0,050$. Hal ini membuktikan Ha diterima dan Ho ditolak. Hal ini juga mendukung perumusan hipotesis H3 bahwa variabel Motivasi berpengaruh positif dan signifikasi terhadap minat berwirausaha.

\section{KESIMPULAN}

Berdasarkan analisis dan pembahasan maka dapat disimpulkan: a. Hasil penelitian menunjukkan bahwa kepribadian kewirausahaan berpengaruh positif terhadap minat berwirausaha mahasiswa Yogyakarta. Artinya mahasiswa di Yogyakarta sudah memiliki jiwa kewirausahaan, seperti berani mengambil risiko, berorientasi pada hasil, dan penuh percaya diri; b. Hasil penelitian membuktikan bahwa ekspektasi pendapatan yang diharapkan tidak berpengaruh terhadap minat berwirausaha. Terlihat beberapa mahasiswa lebih berkeinginan menjadi karyawan perusahaan dari pada menciptakan lapangan kerja. Mereka percaya bahwa jika mereka mencipt akan lapangan kerja. Pendapatan mereka tidak akan setinggi pendapatan bekerja di perusahaan; c. Hasil penelitian membuktikan adanya pengaruh positif dan signifikan Motivasi terhadap Minat Berwirausaha. Semakin terdorongnya akan motivasi maka akan semakin tinggi jiwa kewirausahaan mahasiswa di Yogyakarta.

\section{DAFTAR PUSTAKA}

Anoraga, B. (2015). Motivasi Kerja Islam Dan Etos Kerja Islam Karyawan Bank Jatim Syariah Cabang Surabaya. Motivasi Kerja Islam Dan Etos Kerja Islam Karyawan Bank Jatim Syariah Cabang Surabaya, 2(Juli), 531-541.

Mahardika, I. G. K., Haris, I. A., \& Meitriana, M. A. (2019). Faktor-Faktor Yang Mempengaruhi Motivasi Dalam Berwirausaha Pada Mahasiswa Pendidikan Ekonomi Undiksha. Jurnal Pendidikan Ekonomi Undiksha, 10(2), 554. https://doi.org/10.23887/jjpe.v10i2.20112

Santosa, T. D. (2016). Faktor-Faktor Yang Berpengaruh Terhadap Minat Berwirausaha Mahasiswa Stmik Duta Bangsa Surakarta. Jurnal Sainstech Politeknik Indonusa Surakarta, 1(5), 17-27.

Setiabudi, K. (2019). Pengaruh Dukungan Keluarga Dankepribadian Wirausaha Terhadapniat Berwirausaha Mahasiswaprogram Studi Manajemen Terakreditasi Â€CEâ̂€ Pada Perguruan Tinggi Swasta Di Kota Surabaya. Agora, 7(1), 287127.

Setiawan, D., \& Sukanti. (2016). Pengaruh Ekspektasi Pendapatan, Lingkungan Keluarga 
PUBLIK: Jurnal Manajemen Sumber Daya Manusia, Adminsitrasi dan Pelayanan Publik Sekolah Tinggi Ilmu Administrasi Bina Taruna Gorontalo Volume VIII Nomor 1, 2021

dan Pendidikan Kewirausahaan terhadap Minat Berwirausaha. Jurnal Profita, 7, 1-12. http://journal.student.uny.ac.id/ojs/ojs/index.php/profita/article/view/5990

Syaifudin, A. (2017). Pengaruh Kepribadian, Lingkungan Keluarga Dan Pendidikan Kewirausahaan Terhadap Minat Berwirausaha Mahasiswa Akuntansi. Profita Edisi 8 Tahun 2017, 3, 1-17.

Zuhrina Aidha. (2016). Pengaruh Motivasi Terhadap Minat Berwirausaha Mahasiswa Fakultas Kesehatan Masyarakat Universitas Islam Negeri Sumatera Utara. Ммит, 1(1), 42-59. 